\title{
Misoprostol for induction of labour: a comparative study of various routes of administration
}

\author{
Bushra Ahmad $^{1 *}$, Chandna Shekhar ${ }^{2}$, Sunita Jindal², Sangeeta Gupta²
}

\author{
${ }^{1}$ Department of Obstetrics and Gynecology, St. Stephen's Hospital, Delhi, India \\ ${ }^{2}$ Department of Obstetrics and Gynaecology ESI PGIMSR Basaidarapur, New Delhi, India
}

Received: 05 August 2017

Accepted: 04 September 2017

\author{
*Correspondence: \\ Dr. Bushra Ahmad, \\ E-mail: bushraahmad2011@rediffmail.com
}

Copyright: (c) the author(s), publisher and licensee Medip Academy. This is an open-access article distributed under the terms of the Creative Commons Attribution Non-Commercial License, which permits unrestricted non-commercial use, distribution, and reproduction in any medium, provided the original work is properly cited.

\begin{abstract}
Background: Oxytocin has been used for labor induction since very long, but with high rates of failed induction. The objective of this study is to compare the safety and efficacy of various routes of misoprostol for induction of labor at term. Design: Prospective randomized study was done at the department of obstetrics and Gynecology at the PGIMSR ESI Basaidarapur, New Delhi between August 2009 and July 2011.

Methods: 150 pregnant women were randomized into three groups each to receive $50 \mathrm{mcg}$ of Misoprostol via oral, sublingual and vaginal routes respectively. Doses were repeated 6 hourly for a maximum of 3 doses till the patient entered active stage of labor (clinically adequate contractions of 3/10 min of $>40 \mathrm{~s}$ duration, and cervical dilatation of with $4 \mathrm{~cm}$ ). Statistical analysis was done using chi-square test and ANOVA (one-way analysis of variance).

Results: Mean number of dosage required for successful induction were significantly less in the vaginal group than oral and sublingual groups (in oral groups A were $2.1 \pm 0.42$, sublingual $1.4 \pm 0.34$, vaginal $1.1 \pm 0.29$ ). The induction to delivery interval was significantly less in vaginal group than oral and sublingual groups (Group A oral 21.06 $\pm 9.22 \mathrm{~h}$, group B sublingual $16.81 \pm 8.08 \mathrm{~h}$, group C vaginal $12.9 \pm 5.16 \mathrm{~h} 0.016$ significant). Rate of caesarean was least in the vaginal group $12 \%$ vs $20 \%$ in oral and $26 \%$ in sublingual. All the three groups showed satisfactory neonatal outcomes.

Conclusions: This study shows that vaginal route of administration of misoprostol is preferable to oral route and sublingual route for induction of labor when used in equivalent dosage of $50 \mathrm{mcg} 6$ hourly, however all three routes are well tolerated with favorable neonatal outcomes.
\end{abstract}

Keywords: Induction of labour, Induction delivery interval, Misoprostol

\section{INTRODUCTION}

For majority of women labor starts spontaneously at or near term and result in vaginal delivery, however because of medical or obstetrics complications of pregnancy, labor induction is often required. Induction of labor is the artificial initiation of labor before its spontaneous onset for the purpose of delivery ofthe feteplacental unit using mechanical or pharmacologic methods. ${ }^{1}$ The success of labor induction depends onthe cervical status at the time of induction. It is generally predicted that the patients with a poor Bishop's score have unacceptably higher rates of failure of induction. ${ }^{2}$

The search for ideal agent, timing and route of administration for the induction of labor has been an ongoing process. Oxytocin has been the commonly used agent in patients with favorable cervix it is not suitable for patients with unfavourable cervix due to high rates of failed induction leading to cesarean section. ${ }^{3}$ Misoprostol is a prostaglandian E1 analogue (methyl- 11a 16 dihydroxy- 16 methyl- 9- oxoprost- 13 enloate). 
'Misoprostol' licensed primarily for the prevention and treatmentof non-steroidal anti-inflammatory drug induced ulcers of gastrointestinal tract, is a promising agent for laborinduction. ${ }^{4}$ Misoprostol has uterotonic and cervical ripening actions. It has been shown to have benefits of high efficacy, less sixde effects, economical, does not require refrigeration for storage and easy to administer.

Misoprostol is conveniently administered through the oral, sublingual, buccal, vaginal and rectalroutes. ${ }^{4}$ It is inexpensive, easily stored at room temperature and has few systemic side effects.

In the present study, we attempt to compare the efficacy, safety and patient's acceptability of $50 \mu \mathrm{g}$ of oral, sublingual and vaginal administration of Misoprostol for induction of labor at term.

\section{METHODS}

The study was conducted on 150 pregnant women at term in department of Obstetrics and Gynecology, ESIPGIMSR Basaidarapur New Delhi over a period of two years (August 2009 to July 2011). Ethical committee approval was taken. After getting full informed consent, the subjects were randomly assigned to three groups (oral, sublingual and vaginal) to receive Misoprostol $50 \mu \mathrm{g}$ each. A detailed history followed by general physical examination was done to rule out any cardiorespiratory, hepatic and renal disease, obstetrical examination included P/A - for fundal height, lie, presentation and fetal heart sound. P/V - examination was done for assessing bishop's score and pelvis. Routine biochemical investigations include $\mathrm{ABO} / \mathrm{Rh}, \mathrm{Hb}, \mathrm{BT}$, CT, Urine examination and obstetrical USG was done.

\section{Inclusion criteria}

- Pregnant women at $>37$ weeks of period of gestation for induction of labor

- Singleton pregnancy

- Cephalic presentation

- Bishop Score $<8$

- Reactive non-stress test

- Clinically adequate pelvis.

\section{Exclusion criteria}

- Non-reassuring fetal heart pattern

- Contraindications for vaginal delivery (placenta previa, active herpes infection, cephalopelvic disproportion).

- Heart disease in mother

- Previous uterine scar, LSCS, Myomectomy, Hysterotomy and Known allergy to prostaglandins.

The patients were randomly allocated to either Group A $(n=50)$ who received oral tablet misoprostol $50 \mathrm{mcg}$ repeated every 6hours for maximum three doses, Group $\mathrm{B}(\mathrm{n}=50)$ who received sublingual tablet misoprostol 50 mcg every 6 hours for maximum of three doses and Group $\mathrm{C}(\mathrm{n}=50)$ who received vaginal tablet misoprostol $50 \mathrm{mcg}$ every 6 hours for maximum of three doses.

Basic demographic data was noted and routine investigations were done. Each patient was assigned a serial number. The route of administration was decided according to the group in which number was written in the random number table. An informed consent was obtained. A reassuring fetal heart rate was confirmed with a cardiotocography. A per vaginal examination was done and Bishop Score calculated.

Patient was told to lie supine for half an hour in vaginal route. Time of induction was noted. The Modified Bishop's score was determined. Each patient was questioned in detail and examined thoroughly.

The patient was monitored on a cardiotocograph for 30 minutes after instillation of a dose of misoprostol and as and when required.

Patient was considered to be in active labor if she had painful uterine contractions of $3 / 10 \mathrm{~min}$ of $40 \mathrm{~s}$ duration.

The women were assessed per vaginally under asepsis 6 hours after the last misoprostol dose.

\section{Repeat dose was administered if}

- $\quad$ Bishop score $<8$

- Uterine contractions of less than moderate intensity for $<30$ seconds duration with a frequency of $<3$ per 10 minutes

- Cervix unfavorable for amniotomy or intact membranes.

Amniotomy was done if cervix was $>3 \mathrm{~cm}$ dilated. Oxytocin was administered if after amniotomy, the patient failed to have good/moderate uterine contractions with a frequency of at least 3 per 10 minutes and at least 2 hours after last dose of misoprostol. If the cervix was not favorable for artificial rupture of membranes after the stipulated three doses, the induction was considered to have failed.

A further dose was withheld in case of tachysystole, hypertonus or hyperstimulation or if patient was in progressive active labor and spontaneous rupture of membranes.

Patients were monitored till patient delivered vaginally or by Caesarean section. The outcome was measured as primary and secondary outcome

\section{Primary outcomes}

- Time take from administration of first dose to vaginal deliver

- Mode of delivery 


\section{Secondary outcomes}

- Rise in Bishop Score

- Number of doses required

- Need for Oxytocin augmentation

- Incidence of tachsystole, hyper tonus, hyper stimulation

- Neonatal outcomes- Apgar score at 5 minutes, presence of meconium, need for resuscitation, admission NICU

- Patient acceptability and preference for the same route of administration for any subsequent induction.

\section{Statistical analysis}

The data analysis was done using software SPSS (version 11). Chi-square test was done to compare the categorical variables among the groups. ANOVA (one-way analysis of variance) was done to compare the baseline characteristics of patients and time to delivery among the three groups.
Multiple pair wise group comparison was done. Median Bishop Score difference among the groups was analyzed using Kruskal-Wallis non-parametric ANOVA. P value $<0.05$ was considered significant.

\section{RESULTS}

The demographics with regard to age, period of gestation, parity, Bishop Score and indication for induction of labor were similar in all the three groups. (Table 1).

The mean age of patients was $26.10 \pm 3.47$ years in oral group, 23.36 \pm 3.02 years in sublingual group and $23.94 \pm 2.88$ years in the vaginal group ( $p$ value 0.056 ). The mean period of gestation was $38.81 \pm 1.16$ weeks in the oral group, $39.41 \pm 1.51$ weeks in sublingual and $38.97 \pm 1.33$ weeks in the vaginal group ( $p$ value 0.074 ). The mean parity in oral group was $0.80,0.56$ in sublingual group and 0.54 in vaginal group ( $\mathrm{p}$ value 0.277). The mean Bishop was $3.12 \pm 0.85$ in oral group, $3.06 \pm 0.87$ in sublingual group and $3.62 \pm 1.83$ in the vaginal group ( $\mathrm{p}$ value 0.056 ).

Table 1: Demographic profile.

\begin{tabular}{|lllcl|}
\hline Variable & Group A & Group B & Group C & P value \\
\hline Maternal age (yrs) & $26.10 \pm 3.47$ & $23.36 \pm 3.02$ & $23.94 \pm 2.88$ & 0.56 \\
\hline Period of gestation(wks) & $38.81 \pm 1.16$ & $39.41 \pm 1.51$ & $38.97 \pm 1.33$ & 0.74 \\
\hline Pre-induction Bishop score & $3.12 \pm 0.85$ & $3.06 \pm 0.87$ & $3.62 \pm 1.83$ & 0.56 \\
\hline
\end{tabular}

Table 2: Number of doses required for successful outcome, mode of delivery, induction-delivery interval.

\begin{tabular}{|lllll|}
\hline Variable & Group A & Group B & Group C & P value \\
\hline Mean no of doses & $2.1 \pm 0.42$ & $1.4 \pm 0.34$ & $1.1 \pm 0.29$ & $<0.005$ \\
\hline Induction- delivery (Hours) & $21.06 \pm 9.22$ & $16.81 \pm 8.08$ & $12.9 \pm 5.16 \mathrm{~h}$ & $<0.001$ \\
\hline Spontaneous vaginal delivery & 40 & 35 & 40 & \\
\hline Instrumental vaginal delivery & 0 & 2 & 4 & \\
\hline Cesarean Section & 10 & 13 & 6 & $<0.05$ \\
\hline Induction to delivery interval & $21.06 \pm 9.22$ & $6.81 \pm 8.08$ & $12.90 \pm 5.16$ & 30 \\
\hline Oxytocin augmentation (no of cases) & 20 & 35 & & \\
\hline
\end{tabular}

Most common indication for induction of labor was postdated pregnancy in 17 patients $(34 \%)$ in oral group, $20(40 \%)$ in sublingual group and $18(36 \%)$ in vaginal group. The difference was not statistically significant. The other indications were Pre-eclampsia, Oligo hydroamnios, intrauterine growth retardation, Bad Obstetric history, decreased fetal movements, Intrahepatic cholestasis of pregnancy, RH Iso immunization and Chronic hypertension.

The mean number of doses required for successful induction was 2.1 in oral group, 1.4 in sublingual and 1.1 in the vaginal group. The mean dose required for successful induction was significantly less in the vaginal group than oral and sublingual groups (in oral groups $\mathrm{A}$ were $2.1 \pm 0.42$, sublingual $1.4 \pm 0.34$, vaginal $1.1 \pm 0.29$ (p value 0.001 between 1 and 2 : 1 and $3,0.021$ between 2 and 3) (Table 2).

The induction to delivery interval was significantly less in vaginal group than oral and sublingual groups (Group A oral $21.06 \pm 9.22 \mathrm{~h}$, group B sublingual $16.81 \pm 8.08 \mathrm{~h}$, group $\mathrm{C}$ vaginal $12.9 \pm 5.16 \mathrm{~h}(\mathrm{p}<0.05)$ (Table 2$)$. On comparing individual groups, significant difference was found between oral and vaginal groups $\mathrm{p}=0.014$.

Mean rise in the Bishop score after 6 hours of misoprostol administration was $1.40 \pm 0.808$ in oral group, $1.59 \pm 0.762$ in sublingual group and $2.06 \pm 1.02$ in the vaginal group $(\mathrm{p}=0.008)$. 
Table 3: Side effects of drugs and neonatal outcomes.

\begin{tabular}{|lllll|}
\hline Variable & Group A & Group B & Group C & Total \\
\hline Nausea & 7 & 2 & 0 & 9 \\
\hline Vomiting & 3 & 1 & 1 & 5 \\
\hline Dizziness & 2 & 1 & 0 & 3 \\
\hline Fever & 0 & 0 & 1 & 1 \\
\hline Hypertonus & 1 & 0 & 0 & 1 \\
\hline Uterine Hyperstimulation & 0 & 2 & 0 & 2 \\
\hline Tachysystole & 1 & 0 & 0 & 1 \\
\hline Neonatal outcomes & & & 2 & 9 \\
\hline Meconium stained liqor & 4 & 3 & 4 & 16 \\
\hline Fetal heart rate abnormalities & 5 & 13 & 6 & 10 \\
\hline Cesarean Section & 10 & 3 & 5 & 1 \\
\hline min Apgar score $<7$ & 2 & 0 & 0 & 4 \\
\hline 5 min Apgar score $<7$ & 1 & 0 & 3 & \\
\hline NICU admission & 1 & & & \\
\hline
\end{tabular}

Table 4: Overview of quality of study determinants, doses and pre-induction Bishop of various studies that compred various routes of misoprostol for labor induction.

\begin{tabular}{|llllll}
\hline $\begin{array}{l}\text { Name of } \\
\text { author }\end{array}$ & $\begin{array}{l}\text { Subject } \\
\text { numbers }\end{array}$ & Dose administered & $\begin{array}{l}\text { Pre-induction } \\
\text { Bishop }\end{array}$ & Randomization & Blinding \\
\hline Adair & $\begin{array}{l}47 \mathrm{oral} / \\
49 \mathrm{vaginal}\end{array}$ & $50 \mathrm{mcg} 4 \mathrm{hrly} / 50 \mathrm{mcg} / 4 \mathrm{hrly}$ & $3.6 / 3.2$ & - & - \\
\hline Wing & $\begin{array}{l}53 \mathrm{oral} / \\
52 \mathrm{vaginal}\end{array}$ & $100 \mathrm{mcg} 6 \mathrm{hrly} / 50 \mathrm{mcg} 4 \mathrm{hrly}$ & $4.1 / 3.8$ & + & - \\
\hline Shetty & $\begin{array}{l}87 \mathrm{oral} / \\
80 \mathrm{sublingual}\end{array}$ & $50 \mathrm{mcg} / 50 \mathrm{mcg}$ & $4.1 / 4.0$ & + & + \\
\hline Carlson & $\begin{array}{l}308 \mathrm{oral} / \\
290 \mathrm{vaginal}\end{array}$ & $100 \mathrm{mcg} 6 \mathrm{hrly} / 50 \mathrm{mcg} 4 \mathrm{hrly}$ & $3.3 / 3.1$ & + & + \\
\hline Caliskan & $\begin{array}{l}50 \text { sublingual/ } \\
50 \text { vaginal }\end{array}$ & $50 \mathrm{mcg} 6 \mathrm{hrly} / 25 \mathrm{mcg} 4 \mathrm{hrly}$ & $2.6 / 2.1$ & + & + \\
\hline Present & $50 / 50 / 50$ & $50 \mathrm{mcg}$ every 6 hourly & $3.12 / 3.06 / 3.62$ & + & + \\
\hline
\end{tabular}

With regard to the need of augmentation with titrated doses of oxytocin $30(60 \%)$ patients required oxytocin in GroupI, 15 (30\%) in group II and $20(40 \%)$ in group III and the difference was not significant (Table 2).

Rates of LSCS were minimum in the vaginal group $6 / 50(12 \%)$, maximum in sublingual route $13 / 50(26 \%)$. In the oral group LSCS was required in 10/50(20\%), but difference between groups was not statistically significant $\mathrm{p}=0.141$.

Very few complications occurred in the form of tachysystole in two patients (4\%) in Group II, hypertonus in one patient $(2 \%)$ in Group I, hyperstimulation in two patients (4\%) in group II Meconium stained liquor in five patients (10\%) group I, eight (16\%) in group II and 3 $(6 \%)$ in group III.

Minimal maternal side effects were noted in the form of vomiting in three $(6 \%)$ in group I and one each in group II and group III respectively. Diarrhoea was seen in only one patient in group III and only one patient had vomiting in Group I. (Table 3). With regard to fetal outcome, fetal heart rate abnormalities were seen in five, seven and four patients in group I, II and III respectively (p value 0.196 ).

The Apgar score at 5 minutes was good in most of the babies with no significant difference between the three groups. One-minute Apgar Score $<7$ was found in two babies in oral group, three in sublingual group and five in vaginal group, but at 5 minutes none of the babies had Apgar score below 8 (Table 3 ).

One baby from oral group and three babies from vaginal group needed NICU admission but all babies were eventually discharged in a good state. No baby from the sublingual group needed NICU admission.

With regard to acceptability there was no significant difference between the three groups ( $p$ value 0.277). After analyzing entire data and keeping all parameters into consideration, it can be concluded that all three routes are well tolerated however Group III i.e. Vaginal Misoprostol Group is most favourable with shortest 
induction delivery interval, reduced LSCS rate, no failure rate, minimal need for oxytocin, lower maternal and fetal complications which was the primary objective of the study.

\section{DISCUSSION}

The use of prostaglandin E1 analogue, Misoprostopl for induction of labor has been quite promising. It is inexpensive can be stored at room temperature, has minimal side effects at low doses, can be administered with ease by various routes like oral, sublingual, vagina, buccal and rectal and more importantly acts to promote cervical ripening and uterine contractions. Doses ranging from $25 \mathrm{mcg}$ to $200 \mathrm{mcg}$ have been used but doses more than $50 \mathrm{mcg}$ is associated with uterine contraction abnormalities, meconium passage and uterine rupture. ${ }^{5}$

We did a Pub Med search for studies comparing the three routes of Misoprostol induction and we found no study comparing all the three routes. There are several studies comparing oral and vaginal misoprostol as well as sublingual and vaginal misoprostol for labor induction. ${ }^{6-12}$

The mean age, parity period of gestation and the initial Bishop score was similar in all the three groups. This distribution was similar to previous studies by Shetty et al studies. $^{12}$

A study by Fletcher $\mathrm{H}$ et al studied Labor induction with intravaginal misoprostol compared with the dinoprostone vaginal insert showed that women who received misoprostol had a higher incidence of vaginal delivery within 12 and 24 hours of prostaglandin application, compared with dinoprostone. ${ }^{13}$ Both modalities had similar incidences of cesarean delivery, uterine hyperstimulation, and fetal tachysystole. There was an increased need for oxytocin augmentation in the dinoprostone group. No significant difference in neonatal outcomes was noted between the 2 groups.

With regard to the number of doses needed for labor induction by Misoprostol we found that vaginal route resulted in delivery with a single dose of misoprostol in $90 \%$ of the patients which was much significantly higher as compared to the oral (40\%) and sublingual $70 \%$ routes respectively. ( $\mathrm{p}$ value $<0.005$ ). The findings were similar to study by Shetty et al who has compared oral vs vaginal with delivery rates of $50 \%$ vs $78.8 \%$ respectively ( $p$ value $<0.05){ }^{12}$ On comparing sublingual with vaginal route in equivalent doses of $50 \mu \mathrm{g}$, Caliskan et al in 2005 found significantly higher dose requirement in the sublingual group $1.9 \pm 1.2$ vs vaginal $1.1 \pm 0.4$ (p value 0.001 ) that was similar to our findings. ${ }^{10}$

Mean number of dosage required in our study for successful induction were significantly less in the vaginal group than oral and sublingual groups in oral groups $\mathrm{A}$ were $2.1 \pm 0.42$, sublingual $1.4 \pm 0.34$, vaginal $1.1 \pm 0.29$. Similar were observations of Wing DA et al. and Janice
S. Kwon et al. where dosage requirement was less in vaginal group than oral group. ${ }^{11}$

With regard to mean induction to delivery interval for successful outcome was longest in the oral group $21.06 \pm$ $9.22 \mathrm{~h}$ followed by sublingual group $16.81 \pm 8.08 \mathrm{~h}$, and least in the vaginal group $12.9 \pm 5.16 \mathrm{~h}$. ( $\mathrm{p}<0.001$ oral vs vaginal and $p$ value 0.56 sublingual vs oral). Similar observations were observed by Shetty et al who found significant difference between oral and vaginal routes but no difference between oral and sublingual routes. ${ }^{12}$

Calisken et al in 2005 found significantly less Induction to Delivery Interval in vaginal when compared to sublingual group..$^{14}$

Oxytocin augmentation was needed in $30(60 \%)$ patients Group I, $15(30 \%)$ in group II and $20(40 \%)$ in group III and the difference was not significant. Similar findings were noted by Adair et al and Carlan et al who did not find significant difference between oral and vaginal group. ${ }^{3}$

Rate of Caesarean section rate in the oral group was $20 \%$, in the sublingual group was $26 \%$ and in vaginal group was $12 \%$. Similar findings were seen by Adiar et al who noted $18 \%$ in oral and $13 \%$ in vaginal and the difference was significant. $^{15}$

Fetal distress was the most common indication for LSCS. A total of $3 / 20(15 \%)$ patients in oral group, 6/20(30\%) in the sublingual group and $3 / 20(15 \%)$ in vaginal group had LSCS for fetal distress.

Fetal outcome data showed no significant difference between three groups with respect to 5 min APGAR score $\leq 7(4 \%$, in Group I, $2 \%$ in group II and $8 \%$ in group III, NICU admissions (4 babies (8\%) in Group I, two babies (4\%) 28 in Group II and five babies (10\%) in group III). Similar results were seen by Carlen et al and Shetty et al. ${ }^{6,12}$

No significant difference was seen in neonatal resuscitation at birth. One $(5 \%)$ in oral, $3(6 \%)$ in sublingual and $5(10 \%)$ babies in vaginal group required resuscitation at birth. Thus, present study shows that the fetal outcome results were also comparable in all three groups. Maternal side effects were also same in the three groups and similar findings were seen in studies by Benette et al and Shetty et al. ${ }^{16,12}$

\section{CONCLUSION}

In conclusion, this study shows that for induction of labor, vaginal misoprostol is preferable to oral and sublingual misoprostol when used in equivalent dosage of $50 \mathrm{mcg}$.

In vaginal route of administration compared to oral route, the number of dosage required is less; induction delivery 
interval is less, less incidence of failed induction and less rate of Cesarean section. Neonatal outcome and maternal side effects are comparable in both groups.

\section{ACKNOWLEDGMENTS}

Authors would like to thank Dr. Sunita Jindal, Dr. Pratiksha, Dr. Sangeeta Gupta, Dr. Shamim Akhtar for their encouragement and support.

\section{Funding: No funding sources}

Conflict of interest: None declared

Ethical approval: The study was approved by the Institutional Ethics Committee

\section{REFERENCES}

1. Rayburn COF. Pre-induction cervical ripening: Basis and methods of current practice. Obstet Gynaecol Survey. 2002;67:683-92.

2. Sanchez- Ramos L, Kuntiz AM, Wears RL. Misoprostol for cervical ripening and labor induction: A meta-analysis. Obstet Gynaecol. 1997;89:633-42

3. Pollnovv DM, BroeKhuizen FF. Randomized double blind trial of prostaglandin E2 intravaginal gel versus low dose Oxytocin for cervical ripening before induction of labor. Am J Obstet Gynaecol. 1996;174:1910-6.

4. Alfirevic Z, Keeney E, Dowswell T, Welton NJ, Dias $\mathrm{S}$, Jones LV, et al. Labour induction with prostaglandins: a systematic review and network meta-analysis. BMJ. 2015;350:h217:350.

5. Fletcher HM, Mitchell S, Simeon D, Freidrick J, Brown D: Misoprostol for labor induction at term. Br J Obstet Gynaecol. 1993;100:641-4.

6. Carlan SJ, Bouldin S, Biust Danielle, O' Brien WF. Safety and efficacy of misoprostol for labor induction. A randomized controlled trial. Obstet Gynaecol. 2001;98:107-12.

7. Jahromi BN, Poorgholam F, Yousefi G, Salarian L. Sublingual versus vaginal misoprostol for the induction of labor at term: a randomized, triple-blind, placebo-controlled clinical trial. Iranian $\mathrm{J}$ Med sci. 2016;41(2):79.
8. Rezaie M, Farhadifar F, Sadegh SM, Nayebi M. Comparison of Vaginal and Oral Doses of Misoprostol for Labour Induction in Post-Term Pregnancies. Journal of clinical and diagnostic research: JCDR. 2016;10(3):QC08.

9. Zhang Y, Zhu HP, Fan JX, Yu H, Sun LZ, Chen L, et al. Intravaginal Misoprostol for Cervical Ripening and Labor Induction in Nulliparous Women: A Double-blinded, Prospective Randomized Controlled Study. Chinese Medic J. 2015;128(20):2736.

10. Hall R, Duarte-Gardea M, Harlass F. Oral versus vaginal misoprostol for labor induction. Obstetr Gynecol. 2002;99(6):1044-8.

11. Jindal P, Avasthi K, Kaur M. A Comparison of Vaginal vs. Oral Misoprostol for Induction of LaborDouble Blind Randomized Trial. J Obstetr Gynecol Ind. 2011;61(5):538-42.

12. Shetty A, Danilien P, Templeton A. A comparison of oral and vaginal misoprostol in induction of labor at term. Br J Obstet Gynaecol. 2001;108:218-24.

13. Fletcher HM, Mitchell S, Simeon D, Freidrick J, Brown D. Intravaginal misoprostol versus dinoprostone as cervical ripening and labor inducing agents. Obstet Gynaecol. 1993;83:244-7.

14. Caliskan E, Bodur H, Ozeren S, Lorakei A, Ozkan, Yucesoy I. Misoprostol 50 $\mathrm{gg}$ sublingually versus vaginally for labor induction at term : A randomized study. Gynaecol Obstet Invest. 2005;59:155-61.

15. Adair CD, Weeks JW, Edwards M. Oral or vaginal misoprostol for induction of labor. A randomized double blind trial. Obstet Gynaecol. 1998;92:810-3.

16. Benett KA, EL More L, Feischman S, Jones D, Lopel JA. Prostaglandin induction in women with prior cesarean delivery increases induction time and risk of uterine rupture. Am J Obstet Gynecol. 2000;182:S130.

Cite this article as: Ahmad B, Shekhar C, Jindal S, Gupta S. Misoprostol for induction of labour: a comparative study of various routes of administration. Int $\mathbf{J}$ Reprod Contracept Obstet Gynecol 2017;6:4583-8. 